\title{
Área legalmente protegida sob conflito: o caso da Reserva de Vida Silvestre Tatu-Bola, Estado de Pernambuco, Brasil
}

\section{Aldenice Correia Lacerda*, Janaina Vital de Albuquerque, Josiclêda Domiciano Galvíncio}

Universidade Federal de Pernambuco. Programa de Pós-Graduação em Desenvolvimento e Meio Ambiente (PRODEMA). Avenida Acadêmico Hélio Ramos s/n, sala 605. Cidade Universitária. Recife-PE. Brasil. (CEP 50670-900). *E-mail: aldenicecs@gmail.com.

Resumo. A criação áreas de proteção é uma das mais eficazes medidas mitigadoras dos problemas ambientais no planeta, porém a criação de unidades de conservação deve seguir os aspectos legais cabíveis em todo o processo de implantação, com a perspectiva de uma gestão equilibrada e a não geração conflitos. A criação da Reserva de Vida Silvestre (RVS) Tatu-Bola (Tolypeutes tricinctus), localizada na Região Semiárida do Estado de Pernambuco, ocorreu em curto prazo, deflagrando conflitos socioambientais com os atores envolvidos (órgãos públicos, pesquisadores e comunidades), resultando na solicitação de recategorização da unidade de conservação, pela Secretaria do Meio Ambiente de Pernambuco à Assembleia Legislativa. Essa unidade, antes atendia à categoria de proteção integral, após a recategorização, passará a ser uma unidade de uso sustentável. Os conflitos originaram-se a partir de divergências, sobreposição de áreas e de insuficiência de informação dos órgãos públicos junto às comunidades em torno da reserva. $\mathrm{O}$ artigo tem como objetivo apresentar as informações relacionadas aos conflitos existentes na RVS e discutir a questão legal atual sobre recategorização, a partir de levantamento bibliográfico e discussões sobre a problemática, concluindo que, com a integração dos diversos gestores públicos envolvidos com a questão ambiental, é possível dar continuidade à conservação da biodiversidade da área interagindo com as comunidades envolvidas no contexto.

Palavras-chave: Unidade de conservação; Plano de manejo; Recategorização.

\begin{abstract}
Area legally protected under conflict: the case of TatuBola Wildlife Reserve, State of Pernambuco, Brazil. The creation of protected areas is one of the most effective measures to mitigate environmental problems; however, the establishment of conservation units must follow the legal aspects applicable throughout the implementation process, from a perspective of a balanced management and without conflict. The "Tatu-Bola" (Tolypeutes tricinctus) Wildlife Reserve (WR) was created in a short period, generating socio-environmental conflicts among the actors involved (public agencies, researchers and communities), resulting in the solicitation for recategorizing the conservation unit, by the Secretary of the Environment of Pernambuco to the Legislative Assembly. This
\end{abstract}

Recebido:

$24 / 05 / 2017$

Aceito:

29/06/2017

Publicado:

30/06/2017

Acesso Aberto Artigo completo

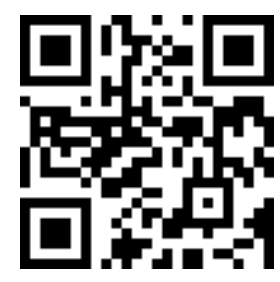

ORCID

(1) 0000-0001-5655-4983 Aldenice Correia Lacerda

(1) 0000-0002-4843-3222 Janaina Vital de Albuquerque

(D) 0000-0002-4204-2685

Josiclêda Domiciano

Galvíncio 
Unit, which was categorized as an integral protection unit, after recategorization, will become a unit of protection for sustainable use. The conflicts were originated from divergences, overlapping areas, and insufficient information from public agencies and communities surrounding the reserve. The aim of this article is to present information related to the existing conflicts in the WR and discuss the current legal issue on recategorization from a bibliographic survey and discussions about the problem, demonstrating that through the integration of the various public agencies involved with the environmental issue, it is possible to support the biodiversity conservation in the area, by interacting with the communities involved in this context.

Keywords: Conservation unit; Management plan; Recategorization.

\section{Introdução}

A criação áreas protegidas é um dos instrumentos mais utilizados em todo o mundo, no sentido de buscar formas alternativas de frear a degradação ambiental. No Brasil, essas áreas tomaram a nomenclatura de unidades de conservação (Santos, 2009), estas áreas são consideradas legalmente protegidas quando decorrentes de lei ou decreto específico, que as denomine como unidade de conservação (Braga, 2009).

Atualmente, a gestão de uma área protegida requer embasamento legal através do enquadramento no Sistema Nacional de Unidades de Conservação (SNUC), instituída pela Lei $n^{\circ}$ 9.985/2000 (Brasil, 2000), que define as unidades de conservação como sendo "espaço territorial e seus recursos ambientais, incluindo as águas jurisdicionais, com características naturais relevantes, legalmente instituídas pelo Poder Público, com objetivos de conservação e limites definidos, sob o regime especial de administração, à qual se aplicam garantias adequadas de proteção”.

O SNUC agrupa as unidades de conservação em diferentes categorias de manejo, divididas em unidades de proteção integral, que têm como objetivo preservar a natureza, sendo admitido apenas o uso indireto dos seus recursos naturais, e as unidades de uso sustentável, que visam a compatibilizar a conservação da natureza com o uso sustentável de parte dos seus recursos naturais (Rodrigues, 2005). São categorizadas como unidades de proteção integral, as áreas com particularidades ambientais, que geralmente são bastante frágeis e tem a necessidade de maiores cuidados, enquanto que as unidades de uso sustentável são áreas onde há a possibilidade de fazer uso sustentável dos recursos naturais de forma direta, e assim contribuir a conservação da natureza com o uso sustentável de parcela de seus recursos naturais.

O SNUC define que o estado deve conduzir as políticas públicas de áreas protegidas, através da gestão e do manejo de unidades de conservação, por estas estarem em maior parte em sua jurisdição, sob seu controle. Como também a sua recategorização que pode ser concedida as referidas situações, como quando ocorrem conflitos por sobreposição dos perímetros das unidades e restrições das atividades realizadas no local, ou até algum tipo de irregularidade encontrada, que tendem a dificultar a gestão e o desenvolvimento dos objetivos propostos quando da sua criação.

Destarte, esse trabalho possui como objetivo apresentar informações relacionadas aos conflitos existentes na Reserva de Vida Silvestre Tatu-Bola e discutir a questão legal atual, que se refere ao seu processo de enquadramento no Sistema Nacional de Unidades de Conservação (SNUC). 


\section{Material e métodos}

\section{Área de estudo}

A área de estudo está inserida no Bioma Caatinga, na Mesorregião do São Francisco, no perímetro dos Municípios de Petrolina, Lagoa Grande e Santa Maria da Boa Vista, onde se localiza a Reserva de Vida Silvestre Tatu-Bola (Figura 1).

O perímetro possui uma área de 110.110,25 ha, com 425.117.95 m, distante entre 615 e $722 \mathrm{~km}$ do Recife, com altitude entre 300 e 778 m. Inserido na Região Semiárida do Estado de Pernambuco, que apresenta clima tropical semiárido quente, com chuvas de verão e período chuvoso no meses de novembro a abril, precipitação média de 431,8 mm e temperatura média de $26{ }^{\circ} \mathrm{C}$. A vegetação é Caatinga Hiperxerófila, com trechos de Floresta Caducifólia, inserida na Bacia Hidrográfica do Rio São Francisco (SEMAS, 2004).

Esse artigo tem como base 0 levantamento bibliográfico, onde se buscou informações referentes aos aspectos físicos e sociais da área; como também o histórico da criação da unidade de conservação, partindo da idealização a sua concretização, e realizado um estudo da legislação pertinente sobre áreas protegidas no Brasil, observando os fatores que levaram a sua criação e as possíveis causas dos conflitos gerados entre os atores em seu contexto, com o propósito de subsidiar a discussão sobre todos os aspectos que levaram a solicitação recategorização da Reserva de Vida Silvestre Tatu-Bola.

Foi realizada análise visual, a partir de imagem cartográfica, através da análise do mapa representativo da situação dos assentamentos rurais em torno da reserva, gerado pela equipe de pesquisadores descrita no documento proposto para área, apresentado na fase de implantação da unidade (SEMAS, 2014).

Também foi confeccionado mapa de representação do perímetro, utilizando as técnicas de sensoriamento remoto, através de informações do satélite Landsat $5 \mathrm{TM}$, com resolução espectral de $30 \mathrm{~m}^{2}$, o que corresponde a 0,09 ha, exceto para a banda 6 (termal) que tem uma resolução espectral de $120 \mathrm{~m}^{2}$, correspondente a 1.40 ha. As imagens foram adquiridas gratuitamente através do site do Instituto de Meteorologia de Pernambuco (IMPE, 2015) e processados pelo software Esdras 9.1.
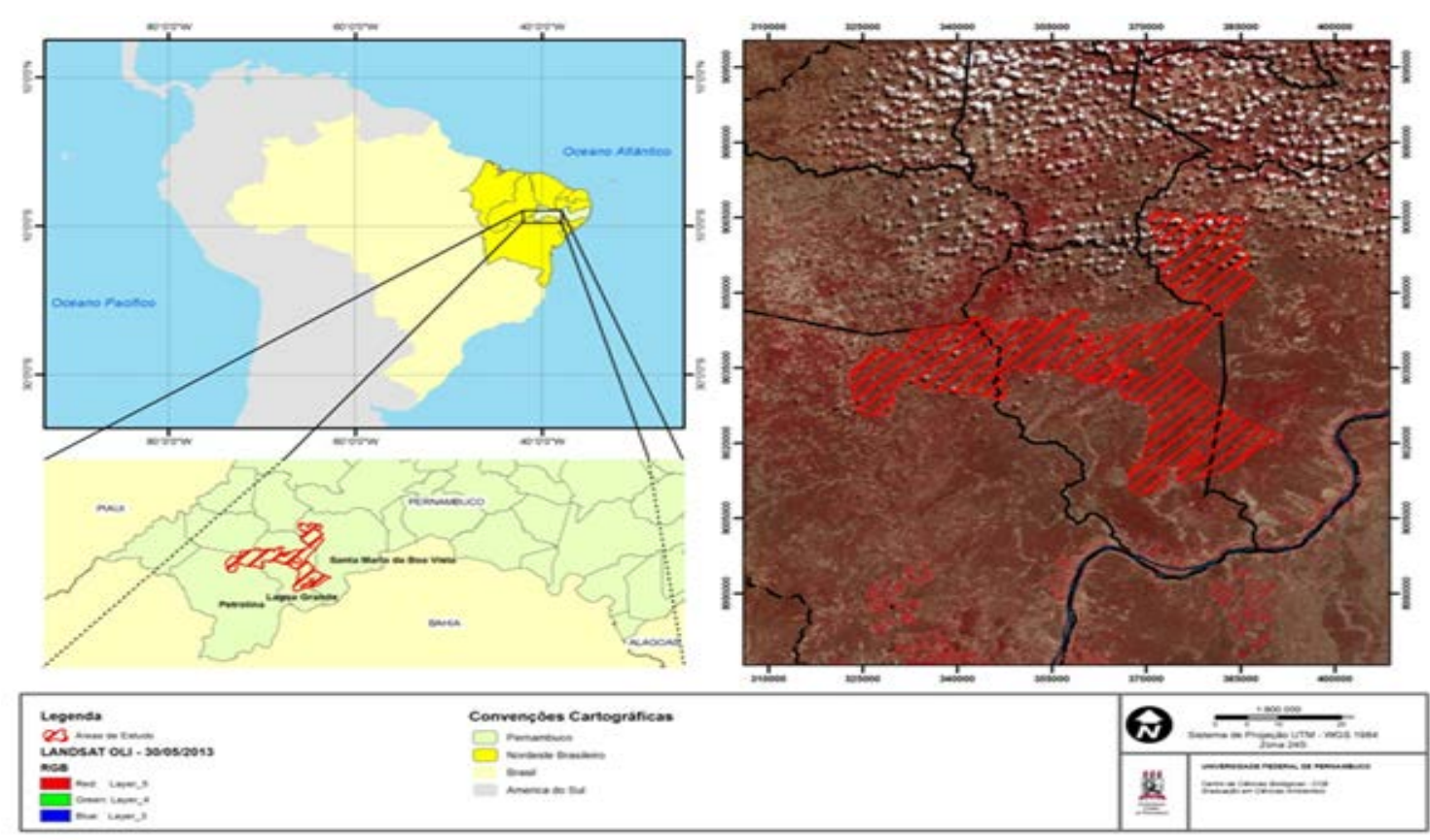

Figura 1. Mapa de representação da área do perímetro da Reserva de Vida Silvestre Tatu-Bola. 


\section{Resultados}

\section{Criação Reserva de Vida Silvestre Tatu-Bola}

A proposta de criação de uma unidade de conservação para a conservação do tatu-bola (Linnaeus, 1758) (Mammalia: Cingulata: Chlamyphoridae) surgiu depois de sua indicação como mascote da Copa do Mundo de 2014, em 2012, por Melo et al. (2014).

A partir de estudos prévios e campanhas para conservação dessa espécie, realizados pela Secretaria de Meio Ambiente e Sustentabilidade (SEMAS) do Estado de Pernambuco, com a colaboração de pesquisadores do Centro de Referência para Recuperação de Áreas Degradadas (CRAD), da Universidade Federal do Vale do São Francisco (UNIVASF), da Universidade Federal de Pernambuco (UFPE) e da Universidade Rural de Pernambuco (UFRPE), em conjunto com o Instituto Nacional de Colonização e Reforma Agrária (INCRA, Petrolina), da Agência Estadual de Meio Ambiente (CPRH) de Pernambuco, do Instituto de Terras e Reforma Agrária do Estado de Pernambuco (ITERP) e das Prefeituras Municipais de Petrolina, Lagoa Grande e Santa Maria da Boa Vista, a Reserva de Vida Silvestre Tatu-Bola foi criada, através do Decreto n ${ }^{\circ}$ 41.546, 16 de março de 2015 (Pernambuco, 2015) (SEMAS, 2014).

\section{Sobre a espécie}

O tatu-bola T. tricinctus é encontrado na Caatinga e em algumas áreas do Cerrado, e é espécie endêmica no Brasil, constando na Lista Oficial da Fauna Brasileira Ameaçada de Extinção vigente, estabelecida pela Portaria ${ }^{\circ}$ 444/2014, do Ministério do Meio Ambiente (MMA, 2014).

No Livro Vermelho da Fauna Brasileira Ameaçada de Extinção (Machado et al., 2008: 709) e na revisão da IUCN está categorizado como "Vulnerável" (VU), pelo critério A2cd (redução da população com um declínio continuado). Na recente avaliação para atualizar a lista oficial de espécies ameaçadas no Brasil, T. tricinctus foi indicado como "Em Perigo" (EN), também pelo critério A2cd, por estimar-se que sua população em ambiente natural tenha sido reduzida, em pelo menos 50\%, nas últimas três gerações devido principalmente à perda de hábitat (ICMBio, 2009).

\section{A proposta de criação}

A Reserva de Vida Silvestre TatuBola surgiu com intuito de aumentar o número de áreas de preservação nessa região, de fundamental importância para conservação da biodiversidade no Estado de Pernambuco, que segundos os idealizadores tinham os seguintes objetivos:

I. Conservar amostras significativas das caatingas de Pernambuco, preservando seu patrimônio genético e recursos naturais;

II. Proteger ambientes naturais onde se assegurem condições para a existência ou reprodução de espécies ou comunidades da flora local e da fauna residente ou migratória;

III. Proteger e conservar espécies raras e endêmicas, em perigo ou ameaçadas de extinção;

IV. Proteger a área de ocorrência do tatu-bola (Tolypeutes tricinctus), diminuindo a pressão de caça, reduzindo a perda de habitat e favorecendo o repovoamento;

V. Promover atividades recuperação ambiental e de educação ambiental, que proporcionem à comunidade local a compatibilização de suas atividades com a conservação dos recursos naturais e aos visitantes, informações sobre o bioma e sua biodiversidade;

VI. Estimular a substituição de espécies exóticas por espécies nativas;

VII. Estimular a pesquisa científica e a produção de conhecimento sobre as caatingas, em especial do sertão do São Francisco de Pernambuco, inclusive seus aspectos socioeconômicos e culturais. (SEMAS, 2014).

Esta unidade de conservação está inserida numa área de Caatinga que comporta uma diversidade de espécies endêmicas, tanto da fauna como da flora. Além do tatu-bola T. tricinctus, existem outras espécies sob risco de extinção na área, como a onça-de-bode Puma concolor greenie e o porco-queixada Tayassu pecari (SEMAS, 2014). 
Atualmente, a maneira mais eficaz de se preservar a biodiversidade como um todo (organismos vivos individualmente, sua variabilidade genética e suas populações) é através das comunidades naturais intactas ou pouco alteradas (Leite et al., 2011). E só através de implantação de um maior número de UCs em áreas de relevante vulnerabilidade, recorrendo a planos de manejos que englobe todos os fatores ambientais inseridos na problemática, através de uso de tecnologias, como monitoramento e também de educação ambiental, que será possível conseguir conservar e recuperar áreas e salvar espécies vulneráveis da extinção.

\section{unidade}

Sobre a área em torno da

Em torno da Reserva de Vida Silvestre Tatu-Bola existem 51 projetos de assentamentos criados pelo Instituto Nacional de Colonização e Reforma Agrária (INCRA), comunidades quilombola, comunidades indígenas, colônias de pescadores, e suas principais atividades econômicas realizadas são a agricultura de sequeiro, a criação de bovinos, caprinos e ovinos e as localizadas próximas a corpos d'água, desenvolvem, também, cultivo em áreas irrigadas.

Os assentados encontram-se na Subzona Assentamentos da Reforma Agrária, nas margens do Rio São Francisco, principalmente- em Santa Maria da Boa Vista e Lagoa Grande, que correspondem à zona de sequeiro, Subzona Reassentamentos da Companhia Hidro Elétrica do São Francisco (CHESF), nos Municípios de Santa Maria da Boa Vista, Fulgêncio, e os indígenas são encontrados na Subzona Ilhas, especialmente no Município de Cabrobó.

No entanto, a agricultura praticada por esses produtores familiares, possuem características sociais, culturais, técnicos e econômicos bem diferenciados em suas atividades irrigantes, no que se faz necessário uma integração conjunta na implantação de políticas públicas, para que se possa contextualizar a problemática, de forma a encontrar soluções que possam auxiliar na preservação da biodiversidade, sem comprometer as atividades econômicas e o desenvolvimento local. Ainda vale ressaltar que alguns trechos dos assentamentos estão dentro do perímetro da unidade de conservação, que constitui áreas que serão designadas como reserva legal de cada assentamento.

\section{Da gestão}

A administração da unidade de conservação é de responsabilidade da Agência Estadual do Meio Ambiente (CPRH) de Pernambuco, que deve elaborar o plano de manejo e nomear o conselho gestor, devendo ter a participação de atores governamentais das três esferas do poder público, municipal, estadual, e federal, que participam das políticas públicas, bem como de atores das organizações da sociedade civil organizada, como empresários, sindicatos dos trabalhadores associações, instituições de pesquisa, cooperativas, imprensa, entre outros, do modo que é assegurada pela Lei $\mathrm{n}^{\circ}$ 13.787/2009 (Pernambuco, 2009), que instituiu o Sistema Estadual de Unidades de Conservação (SEUC), determinando que a gestão participativa pelo conselho gestor da unidade atuará visando à conservação do patrimônio ambiental da unidade, participando da elaboração do plano de manejo.

\section{A problemática}

Desde sua criação, a Reserva de Vida Silvestre Tatu-Bola, foi alvo de reclamações, tendo sua gestão marcada pela disseminação de diversos conflitos, que foram ocasionados, em boa parte, pela falta de informação fornecida pelo Poder Público para as comunidades, que residiam em áreas sobrepostas à UC, bem como por seu processo de implantação ter sido realizado em um curto período de tempo.

A população alegou não ter sido consultada e nem conhecer os detalhes da implantação da reserva, a restrição para a realização de atividades de rotina, como a criação de caprinos, por exemplo, que acabou propiciando revolta. $\mathrm{O}$ assunto esteve em pauta, em algumas reuniões ordinárias do Conselho Estadual do Meio Ambiente (CONSEMA) de Pernambuco. 
Representante da Comunidade de Baixa Alegre, em Petrolina, enfatizou que os sertanejos querem integrar projetos de proteção ambiental, mas que não podem deixar de ter seus direitos assegurados. "Ninguém aqui é contra preservação. Todos nós queremos ajudar. Mas temos que refletir que toda preservação ambiental não deve se esquecer de cuidar do ser humano. Meio ambiente representa a conjunção e o equilíbrio entre estas partes: recursos naturais e o homem", enfatizou o representante na reunião do CONSEMA (Nilberto Ribeiro ${ }^{1}$ ).

\section{A proposta de recategorização}

A proposta apresentada na reunião do Conselho Estadual de Meio Ambiente (Consema) de Pernambuco, em 21 de setembro de 2015, se refere à recategorização da Reserva de Vida Silvestre Tatu-Bola, anteriormente enquadrada na categoria de proteção integral, em uma área de proteção ambiental (APA), que permite uma maior flexibilização das atividades humanas, sugerindo que uma unidade de conservação de uso sustentável abrigará subáreas específicas de proteção integral, num perímetro onde não há produção agropecuária, permitindo a conciliação da produção agrícola e a conservação da Caatinga. Que é um bioma que vem sofrendo grande devastação, em consequência das atividades antrópicas, e de segundo Araújo (2011), grandes extensões da Caatinga são destruídas para usar como lenha, o que gera perda nas condições ecológicas locais e também a de valor do recurso do ponto de vista da sua evolução e de uso para humanidade.

Ao criarmos o Refúgio de Vida Silvestre Tatu-Bola tínhamos a intenção de promover a conservação do Meio Ambiente e, ao mesmo tempo, melhorar a vida do homem sertanejo. Mas, pelo que pudemos perceber, houve problemas nas informações repassadas para as comunidades e o

\footnotetext{
${ }^{1}$ Nilberto Ribeiro, representante da Comunidade da Baixada Alegre, Petrolina, na Reunião do CONSEMA.
}

resultado é o que vemos hoje: muitas dúvidas e incertezas. Na verdade, o que estamos propondo a vocês é a construção conjunta de um projeto moderno de desenvolvimento sustentável. Nosso diálogo tem que ser permanente e transparente e nós vamos acatar o que vocês decidirem" (Sérgio Xavier, 2015) ${ }^{2}$.

A proposta de recategorização da Reserva de Vida Silvestre Tatu-Bola foi decidida por uma comissão de representantes de sindicatos, prefeituras, vereadores, instituições de ensino, agricultores rurais, com a presença do Secretário Estadual do Meio Ambiente, que sugeriu que fossem feitas algumas alterações no Decreto $\mathrm{n}^{\circ}$ 41.546/2015 (Pernambuco, 2015), explicando que o processo de revogação não consistia em um ato simples e que teria que passar pela Assembleia Legislativa para aprovação (Sérgio Xavier, 2015²).

\section{Embasamento jurídico para recategorização}

A conservação e manejo sustentável do meio ambiente estão explicitados pela Lei $\mathrm{n}^{\circ}$ 6.938/1981, que estabelece a Política Nacional de Meio Ambiente, e pela Lei $\mathrm{n}^{\circ} 9.985 / 2000$, que criou o Sistema Nacional de Unidades de Conservação da Natureza (SNUC). Complementam com o capítulo VI, da Constituição Federal de 1988, que trata do Meio Ambiente, para todas as iniciativas de planejamento direcionadas às unidades de conservação da natureza.

\begin{abstract}
Art. 225.
$\S 1^{\circ}$ Para assegurar a efetividade desse direito, incumbe ao Poder Público: (...) III - definir, em todas as unidades da Federação, espaços territoriais e seus componentes a serem especialmente protegidos, sendo a alteração e a supressão permitidas somente através de lei, vedada qualquer utilização que comprometa a
\end{abstract}

\footnotetext{
${ }^{2}$ Sérgio Xavier, Secretário do Meio Ambiente, no discurso da reunião do CONSEMA, em 21 de setembro de 2015.
} 
integridade dos atributos que justifiquem sua proteção (Brasil, 2000).

Na Tabela 1, encontra-se a especificação de cada grupo de unidades de conservação, de acordo com sua categoria e finalidade de acordo com a lei que criou o SNUC (Lei ${ }^{\circ}$ 9.985/2000).

Sendo assim, com a recategorização da reserva de vida silvestre, que se encontra na categoria de área de proteção integral, a Reserva de Vida Silvestre Tatu-Bola terá embasamento garantido por lei, para que haja a recategorização, de unidade de proteção de uso sustentável, no caso a unidade passará a ser enquadrada como Área de Proteção Ambiental (APA).

De acordo com Marçal e Dios (2010) a situação das unidades de conservação no Brasil é ainda muito precária, pois, além da pouca representatividade dessas áreas em relação ao tamanho do país, muitas não foram efetivamente implantadas nem estruturadas, nem tampouco inventariadas adequadamente.

Tabela 1. Categorias de proteção criadas a partir do SNUC.

\begin{tabular}{|c|c|c|}
\hline Grupo & Categoria & Finalidade de Manejo \\
\hline \multirow{5}{*}{ Proteção Integral } & Estação Ecológica & $\begin{array}{l}\text { Preservação da natureza e realização de pesquisas } \\
\text { cientificas. }\end{array}$ \\
\hline & Reserva Biológica & Preservação integral da biota e demais atributos naturais. \\
\hline & Parque Nacional & $\begin{array}{l}\text { Preservação de ecossistemas naturais de grande relevância } \\
\text { ecológica e beleza cênica. }\end{array}$ \\
\hline & Monumento Natural & $\begin{array}{l}\text { Preservação de sitios naturais raros, singulares ou de grande } \\
\text { beleza cênica. }\end{array}$ \\
\hline & Refúgio de Vida Silvestre & Proteção de ambientes naturais. \\
\hline \multirow{7}{*}{ Uso Sustentável } & $\begin{array}{l}\text { Área de Proteção } \\
\text { Ambiental }\end{array}$ & $\begin{array}{l}\text { Proteger a diversidade biológica, disciplinar o processo de } \\
\text { ocupação e assegurar a sustentabilidade do uso dos recursos } \\
\text { naturais. }\end{array}$ \\
\hline & $\begin{array}{l}\text { Área de Relevante } \\
\text { Interesse Ecológico }\end{array}$ & Manter ecossistemas e regular o uso da área. \\
\hline & Floresta Nacional & $\begin{array}{l}\text { Uso múltiplo sustentável dos recursos florestais e pesquisa } \\
\text { cientifica. }\end{array}$ \\
\hline & Reserva Extrativista & $\begin{array}{l}\text { Proteger o meio de vida e a cultura das populações } \\
\text { extrativistas tradicionais. }\end{array}$ \\
\hline & Reserva de Fauna & $\begin{array}{l}\text { Estudos técnicos científicos sobre manejo econômico } \\
\text { sustentável dos recursos faunisticos. }\end{array}$ \\
\hline & $\begin{array}{l}\text { Reserva de } \\
\text { Desenvolvimento } \\
\text { Sustentável }\end{array}$ & $\begin{array}{l}\text { Preservar a natureza, assegurar condições para reprodução e } \\
\text { melhoria dos modos e da qualidade de vida e da exploração } \\
\text { dos recursos naturais das populações tradicionais. }\end{array}$ \\
\hline & $\begin{array}{l}\text { Reserva Particular do } \\
\text { Patrimônio Natural }\end{array}$ & diversidade biológica. \\
\hline
\end{tabular}

Fonte: Lei n ${ }^{\circ}$ 9.985/2000 (Brasil, 2000).

Estudos como os de Sbroglia e Beltrame (2012) retratam processos onde houve solicitação de recategorização de da UC, como a do Parque Municipal da Lagoa do Peri, Florianópolis-SC, que passaria a categoria de APA ou/e Monumento Natural, devido à sobreposição de área e de interesses variados comumente conflitantes entre os diferentes atores sociais envolvidos.
Como também a recategorização e redefinição de limites da Reserva Florestal do Parima em Roraima, criada em 1961 para Floresta Nacional (Brasil, 2010). O conflito ocasionado se refletiu porque grande parte da área ficou sobreposta com a Terra Indígena Ianomami, homologada em 1992.

Cabe ressaltar que de acordo com a União Internacional para a Conservação 
(Dudley, 2008), os objetivos primários de conservação das áreas protegidas são:

- manutenção dos processos ecológicos vitais e dos sistemas de suporte à vida;

- preservação da diversidade biológica e genética;

- proteger valores estéticos e ecossistemas naturais;

- conservar bacias hidrográficas e manter a produção sustentada de água quantidade e qualidade;

- controle de erosão, sedimentação e degradação de solos;

- manutenção da qualidade do ar;

- proteção de habitats representativos de espécies raras e/ou em perigo de extinção;

- provimento de oportunidades para o ecoturismo e recreação;

- provimento de oportunidades para a pesquisa, educação e monitoramento ambiental;

- contribuição para o desenvolvimento sustentável;

- proteção de patrimônios naturais e culturais;

- manutenção de opções abertas para o futuro.

Estes objetivos formam um conjunto de fatores que devem ser levados em consideração no processo de implantação de uma unidade de conservação, para que nenhuma lei venha ser infligida ou venha causar conflitos futuros, e que os instrumentos de controle e de comando sejam aplicados de cordo com a legislação visando à conservação dos recursos naturais e ao bem-estar das comunidades inseridas no contexto.

\section{Da anulação}

A recategorização da Reserva de Vida Silvestre Tatu-Bola foi solicitada pelo Conselho Estadual de Meio Ambiente (CONSEMA) de Permambuco à Assembleia Legislativa do Estado, para ser transformada em uma área de proteção ambiental (APA) e, de acordo com o Secretário do Meio Ambiente Sérgio Xavier, foi estabelecido um prazo de 180 dias, a contar da data da realização da reunião do conselho, para que o grupo elabore um Projeto de Lei a ser encaminhado ao Governo do Estado de Pernambuco, para e que seja votado pela Assembleia Legislativa do Estado.

Em seguida devem ser iniciados estudos mais detalhados para definir os mosaicos de proteção integral, que precisam ser implantados no perímetro da APA, que deverá passar por um novo processo de licenciamento para que seja caracterizada áreas de proteção integral dentro do mosaico, que referencie as áreas que possuem um grande acervo de vegetação conservada. "Após o prazo e ajustes, vamos contatar o Plano Manejo para definir toda a potencialidade da Caatinga e desenvolver editais, para assim, fazer a criação do conselho gestor da unidade de conservação", relata o Secretário. Ficando a decisão final aguardada aos termos da Assembleia Legislativa do Estado no prazo estipulado a partir da solicitação (CONSEMA, 2015).

\section{A opinião de pesquisadores sobre a recategorização}

Os pesquisadores envolvidos na criação da unidade de conservação questionaram a solicitação de mudança da categoria da unidade, através da elaboração de um documento de repúdio acreditando, que está mudança está sendo proposta por haver manobra política, movida por interesses escusos. No referido documento o conteúdo vem a esclarecer à população os seguintes pontos: todos os estudos tiveram o cuidado de excluir da área proposta, (a) zonas de solos férteis aptas à agricultura, (b) áreas de assentamentos rurais, (c) áreas com grande densidade de estradas (Melo et al., 2016).

Essas medidas permitiram selecionar a maior quantidade de área com o menor impacto social possível para a criação da área protegida.

Os estudos realizados pelos pesquisadores que participaram da criação da reserva, foi apresentado em audiências públicas nos municípios de Lagoa Grande e Santa Maria da Boa Vista, amplamente divulgados, com intuito de que o processo de criação fosse realizado de forma 
transparente, de forma rara em processos de criação de áreas protegidas no Brasil.

Também enfatizam que a implantação de uma APA, é mais justificada em áreas bastante povoada e com diferentes tipos de uso de solo, e que esse tipo de proteção não se adéqua a áreas com recursos naturais importantes, que precisam de uma proteção mais eficaz, e a área destinada a Reserva de Vida Silvestre Tatu-bola, possui todos os requisitos para o grupo de proteção integral, por ter baixa densidade populacional, poucas estradas e solos inférteis para agricultura (Melo et al., 2016).

Como também refere à exclusão dos grupos de pesquisas envolvidas na criação da RVS dos diálogos pelos órgãos públicos, não comparecendo em palestras realizadas por entidades civis que tratam da questão. E fazem cobranças no sentido de que os debates em relação à transparência em torno da Reserva de Vida Silvestre Tatu-Bola e do boicote em relação às opiniões técnicas que foram realizadas a portas fechadas.

Durante todo o processo, houve uma indução a insuflar os produtores rurais a temer a desapropriação, uma vez que muitos assentados ainda não estão de posse de documentos legais de suas propriedades, levando até mesmo a ocorrer ameaças de morte aos pesquisadores que estudavam na área, bem como relatam a indignação com o apoio da Secretaria de Meio Ambiente e Sustentabilidade (SEMAS), órgão que participou da criação e gestão, se posicionar a favor da recategorização, diminuindo a importância da unidade de conservação (Melo et al., 2016).

Assim como reforçaram a importância da geração do plano de manejo de forma transparente e participativa, conciliando conservação e produção local sustentável, documento este redigido e assinado por pesquisadores das Instituições,
UFPE, UNIVASF, Universidade Federal da Paraíba (UFPB) e ICMBio, pode ser encontrado na íntegra no site 3 .

\section{Energia eólica}

Outro agravante também tem sido relacionado à solicitação da recategorização da Reserva de Vida Silvestre Tatu-Bola em área de proteção ambiental (APA), é que estudos apontam que a área em questão, é uma zona que exerce uma grande influência de ventos quanto a sua localização e relevo, por ter um grande potencial para instalação de usinas de energia eólica. $\mathrm{O}$ vento é o ar em movimento resultado do deslocamento de massas de ar, devido aos efeitos das diferenças de pressão atmosférica entre regiões distintas e ele é influenciado pelas variações do relevo do local e pela rugosidade do terreno (Poleto e Vieira, 2010). Devido a esse fator, a veracidade da motivação da recategorização da unidade de conservação sido alvo de indagação pelos pesquisadores envolvidos na criação da unidade, de ser devido aos apelos dos pequenos produtores (Melo et al., 2016).

A ideia de inserir usina de eólicas no Sertão pernambucano vem do fato de que é uma área bastante propícia a instalação das usinas, por se tratar de um empreendimento que não necessita de água, e é vista como uma grande oportunidade para a economia da região (Pernambuco, 2016). Órgãos do governo pretende criar incentivos, segundo o Secretário do Meio Ambiente, Sérgio Xavier, que venham a criar vários incentivos, para atrair investidores, que viabilize a instalação de empreendimento na área da Reserva de Vida Silvestre Tatu-Bola, como um licenciamento simplificado, redução ou isenção de ICMS em investimento em equipamentos para a geração de energia (Pernambuco, 2016).

Mesmo compreendendo que a geração de energia eólica é considerada

\footnotetext{
${ }^{3}$ https://biogeografiadaconservacaoufal.wordpress.co m/2015/11/24/a-tal-da-reclassificacao-a-opiniao-dospesquisadores-sobre-a-recategorizacao-do-refugioda-vida-silvestre-tatu-bola/
} 
energia limpa, a instalação do empreendimento gera impacto ambiental, principalmente se instalado em área protegidas, como no caso da Reserva de Vida Silvestre Tatu-Bola que vai descaracterizar grande parte de áreas florestadas com o desmatamento para a implantação (Pernambuco, 2016).

Contatando o embasamento jurídico consta na Resolução CONAMA n ${ }^{\circ}$ 428/2010:

\begin{abstract}
Art. $3^{\circ}$
$\S 3^{\circ}$ não será considerado baixo impacto, exigindo a apresentação de Estudo de Impacto Ambiental e Relatório de Impacto Ambiental EIA/RIMA, além de audiências públicas, nos termos da legislação vigente, os empreendimentos eólicos que estejam localizados:

IV - em zona de amortecimento de unidades de conservação integral, adotando-se o limite de $3 \mathrm{~km}$ (três quilômetros), a partir do limite da unidade de conservação, cuja zona de amortecimento não esteja ainda estabelecida;

V - em área de ocorrência de espécies ameaçadas de extinção e áreas de endemismo restrito, conforme listas oficiais. (Brasil, 2010).
\end{abstract}

Ressaltando que a área predestinada à instalação do empreendimento abordado, se encontra em uma área de proteção integral, a espera de concretização de recategorização, com apenas um ano de criação, cuja gestão e planos de manejo ainda estão em processo de elaboração.

\section{Considerações finais}

As unidades de conservação são criadas com a finalidade de conservar a biodiversidade, levando em consideração todas as formas de vida existente na área proposta, como também suas interações. Cabe aos órgãos governamentais utilizar de meios justos, para fomentar as adequações necessárias, sem ferir a legislação, implantando uma gestão que venha a conciliar a população com planos de manejo visando à sustentabilidade ambiental.
Estabelecer um direito ambiental sustentável é uma tarefa primordial, contanto que se estabeleçam diretrizes que assegure os direitos dos interessados, como o de propriedade, junto aos órgãos públicos dentro dos princípios da legalidade, e para que sejam assegurados esses direitos, é necessário que haja uma prévia discussão sobre os espaços que sofrerão intervenção e o papel de cada um dentro desse contexto.

O caso da Reserva de Vida Silvestre Tatu-Bola demonstra que ocorreu divergência na criação unidade de conservação, que é alimentada pela falta de integração entre a comunidade existente e os diversos órgãos públicos envolvidos com a questão ambiental da área a ser implantada a unidade. Portanto, deve-se ressaltar a necessidade de uma revisão nos procedimentos de criação da unidade de conservação, para que não ocorra futuros conflitos envolvendo o direito de propriedade, e que possa dar continuidade a conservação da biodiversidade da área, principalmente a espécie símbolo da unidade que além de ser endêmico desse bioma encontra-se na lista vermelha de espécie em extinção, como também possa garantir o desenvolvimento econômico e sustentabilidade local levando em conta todos os aspectos e envolvidos.

\section{Declaração de conflitos de interesse}

As autoras declaram não haver conflitos de interesses.

\section{Referências}

Braga, R. Instrumentos para gestão ambiental e de Recursos Hídricos. 1. ed. Recife: Editora Universitária/UFPE, 2009.

Brasil. Lei $\mathbf{n}^{\mathbf{0}}$ 9.985, de 18 de julho de 2000. Regulamenta o art. 225, § $1^{\circ}$, incisos I, II, III e VII da Constituição Federal, institui o Sistema Nacional de Unidades de Conservação da Natureza e dá outras providências. Disponível em: <http://www.planalto.gov.br/ccivil_03/leis/ L9985.htm>. Acesso em: 04 ago. 2015.

Brasil. Decreto $n^{0} \mathbf{4} .340$, de 22 de agosto de 2002. Regulamenta artigos da Lei $n^{0} 9.985$, de 18 de julho de 2000, que dispõe sobre o Sistema Nacional de Unidades de Conservação da Natureza - SNUC, e dá outras providências. 
Disponível em: <http://www.planalto.gov.br/ ccivil_03/decreto/2002/d4340.htm>. Acesso em: 04 ago. 2015.

Brasil. Decreto no 5.746, de 5 de abril de 2006. Regulamenta o art. 21 da Lei ${ }^{\circ} 9.985$, de 18 de julho de 2000, que dispõe sobre o Sistema Nacional de Unidades de Conservação da Natureza. Disponível em: $<$ http://www.planalto.gov.br/ccivil_03/_Ato200 4-2006/2006/Decreto/D5746.htm>. Acesso em: 04 ago. 2015.

Brasil. Decreto $n^{0}$ 5.758, de 13 de abril de 2006. Institui o Plano Estratégico Nacional de Áreas Protegidas - PNAP, seus princípios, diretrizes, objetivos e estratégias, e dá outras providências. Disponível em: <http://www.planalto.gov.br/ccivil_03/_ato2004 -2006/2006/decreto/d5758.htm>. Acesso em: 04 ago. 2015.

Brasil. Ministério do Meio Ambiente. Estudo para redefinição de limites e recategorização da reserva florestal do Parima. Informações para recategorização e redefinição de limites da Reserva Florestal do Parima (Processo $\mathrm{n}^{\circ}$ 02001.005148/2006-50). 2010. Disponível em: <http://www.icmbio.gov.br/portal/images/ stories/o-que-fazemos/estudoflonaparimafinal.pdf>. Acesso em: 16 maio 2016.

Brasil. Resolução CONAMA n ${ }^{0}$ 462, de 24 de julho de 2014. Estabelece procedimentos para o licenciamento ambiental de empreendimentos de geração de energia elétrica a partir de fonte eólica em superfície terrestre, altera o art. $1^{\circ}$ da Resolução CONAMA n ${ }^{\circ} 279$, de 27 de julho de 2001, e dá outras providências. Disponível em: <http://www.mma.gov.br/port/conama/legiabre. cfm?codlegi=703>. Acesso em: 04 ago. 2015.

CONSEMA - Conselho Estadual de Meio Ambiente de Pernambuco. 45 ${ }^{\circ}$ Reunião Extraordinária CONSEMA-PE. 21/09/2015. Disponível em: <https://www.youtube.com/ watch?v=h9vEW3yo4U0>. Acesso em: 11 maio 2016.

Dios, C. B.; Marçal, M. S. Legislação ambiental e a gestão de unidades de conservação: o caso do Parque Nacional da restinga de JurubatibaRJ. In: Coelho, M. C. N.; Guerra, A. J. T. (Orgs.). Unidades de conservação: abordagens e características geográficas. Rio de Janeiro: Bertrand Brasil, 2009.

Dudley, N. (Ed.). Guidelines for applyng protected area manageament categories. Gland, Switzerland: IUCN, 2008. Disponível em: $\quad<$ https://cmsdata.iucn.org/downloads/ guidelines_for_applying_protected_area_manag ement_categories.pdf $>$. Acesso em: 10 nov. 2015.

ICMBio - Instituto Chico Mendes para a Conservação da Biodiversidade. Sumário executivo do Plano de Ação Nacional para a Conservação do Tatu-Bola. 2014. Disponível em: <http://www.icmbio.gov.br/portal/images/ stories/docs-plano-de-acao/pan-tatu-bola/ sumario-tatu-bola-2014.pdf $>$. Acesso em: 10 nov. 2015

Leite, M. S.; Geiseler, S.; Pinto. S. R. R. Como criar unidades de conservação: guia prático para Pernambuco. 1. ed. Recife: JVL Gráfica e Editora, 2012.

Machado, A. B. M.; Drummond, G. M.; Paglia, A. P. Livro vermelho da fauna brasileira ameaçada de extinção. 1. ed. Brasília: MMA; Belo Horizonte: Fundação Biodiversitas, 2008. v. 2. (Biodiversidade, 19). Disponível em: <http://www.icmbio.gov.br/portal/images/storie s/biodiversidade/fauna-brasileira/livrovermelho/volumeII/Mamiferos.pdf $>$. Acesso em: 28 jun. 2016.

Melo, F. P.; Siqueira, J. A.; Santos, B. A.; Silva, O. A.; Ceballos, G.; Bernard, E. Football and biodiversity conservation: FIFA and Brazil can still hit a green goal. Biotropica, $\begin{array}{llll}\text { v. } 46, & \text { n. } 3, \quad \text { p. 257-259, } 2014 .\end{array}$ https://dx.doi.org/10.1111/btp.12114

Melo, F. P.; Siqueira, J. A.; Santos, B. A.; Silva, O. A.; Ceballos, G.; Bernard, E. Carta de repúdio à Secretaria de Meio Ambiente e sustentabilidade - Semas. 2015. Disponível em: $<$ https://biogeografiadaconservacaoufal.wordpre ss.com/2015/11/24/a-tal-da-reclassificacao-aopiniao-dos-pesquisadores-sobre-arecategorizacao-do-refugio-da-vida-silvestretatu-bola>. Acesso em: 28 jun. 2016.

MMA - Ministério do Meio Ambiente. Portaria $n^{\circ}$ 444, de 17 de dezembro de 2014. Disponível em: <http://www.icmbio.gov.br/ portal/images/stories/biodiversidade/faunabrasileira/avaliacao-do-risco/PORTARIA_No 444_DE_17_DE_DEZEMBRO_DE_2014.pdf >. Acesso em: 28 jun. 2016.

Pernambuco. Lei $\mathbf{n}^{\mathbf{0}}$ 13.787, de 8 de junho de 2009. Institui o Sistema Estadual de Unidades de Conservação da Natureza - SEUC, no âmbito do Estado de Pernambuco, e dá outras providências. Disponível em: $<$ http://legis.alepe.pe.gov.br/arquivoTexto.aspx? tiponorma $=1 \&$ numero $=13787 \&$ complemento $=0$ \&ano=2009\&tipo=\&url=>. Acesso em: 04 ago. 2015. 
Pernambuco. Decreto $\mathrm{n}^{\mathrm{o}}$ 41.546, de 16 de março de 2015. Cria o Refúgio de Vida Silvestre (RVS) Tatu-bola localizado nos Municípios de Lagoa Grande, Santa Maria da Boa Vista e Petrolina, e dá outras providências. Disponível em: <http://legis.alepe.pe.gov.br/ arquivoTexto.aspx?tiponorma $=6 \&$ numero $=415$ 46\&complemento $=0 \&$ ano $=2015 \&$ tipo $=$ TEXTO ORIGINAL>. Acesso em: 04 ago. 2016.

Pernambuco. Projeto de Lei Ordinária $n^{\circ}$ 407/2015. Altera a Lei $n^{0} 11.206$, de 31 de março de 1995, que dispõe sobre a política florestal do Estado de Pernambuco. Disponível em: <http://www.alepe.pe.gov.br/proposicaotexto completo/?docid=B472B7AF6193EA 9A03257EB30074AABA>. Acesso em: 04 ago. 2016.

Poleto, C.; Vieira, A. L. Introdução ao gerenciamento ambiental. Rio de Janeiro: Intercência, 2010.

Rodrigues, J. E. R. Sistema Nacional de Unidades de Conservação. São Paulo: Revista dos Tribunais, 2005.
Santos, L. B. Trilhas da política ambiental: conflitos, agendas e criação de unidades de conservação. Ambien. Soc., v. 12, n. 1, p. 133150, 2009. http://dx.doi.org/10.1590/S1414753X2009000100010

Sbroglia, R. M.; Beltrame, A. V. O zoneamento, conflitos e recategorização do Parque Municipal da Lagoa do Peri. Boletim de Geografia, v. 30, n. 1, p. 5-18, 2012. Disponível em: $<$ http://www.periodicos.uem.br/ojs/index.php/B olGeogr/article/view/11542>. Acesso em: 13 maio 2016.

SEMAS - Secretaria de Meio Ambiente e Sustentabilidade. Refúgio de Vida Silvestre Tatu-Bola. Lagoa Grande e Santa Maria da Boa Vista. Pernambuco. Proposta para Discussão. Recife: SEMAS, 2014. Disponível em: $<$ http://www.cprh.pe.gov.br/ARQUIVOS_ANE XO/Proposta UC Tatu-Bola _ FINAL 05.08.14.pdf $>$. Acesso em 04 ago. 2015. 